\title{
Air quality assessment among populous sites of major metropolitan cities in India during COVID-19 pandemic confinement
}

\author{
Gaurav Pant ${ }^{1}$ (I) $\cdot$ Alka $^{2} \cdot$ Deviram Garlapati ${ }^{3} \cdot$ Ashish Gaur $^{1} \cdot$ Kaizar Hossain $^{4} \cdot$ Shoor Vir Singh $^{1} \cdot$ Ashish Kumar Gupta $^{5}$
}

Received: 12 June 2020 / Accepted: 29 September 2020 / Published online: 11 October 2020

(C) Springer-Verlag GmbH Germany, part of Springer Nature 2020

\begin{abstract}
The present study aims to determine the impact of COVID-19 pandemic confinement on air quality among populous sites of four major metropolitan cities in India (Delhi, Mumbai, Kolkata, and Chennai) from January 1, 2020 to May 31, 2020 by analyzing particulate matter (PM2.5 and PM10), nitrogen dioxide $\left(\mathrm{NO}_{2}\right)$, ammonia $\left(\mathrm{NH}_{3}\right)$, sulfur dioxide $\left(\mathrm{SO}_{2}\right)$, carbon monoxide $(\mathrm{CO})$, and ozone levels. The most prominent pollutant concerning air quality index (AQI) was determined by Pearson's correlation analysis and unpaired Welch's two-sample $t$ test was carried out to measure the statistically significant reduction in average AQI for all the four sites. AQI significantly plummeted by 44\%, 59\%, 59\%, and 6\% in ITO-Delhi, Worli-Mumbai, Jadavpur-Kolkata, and Manali Village-Chennai respectively. The findings conclude a significant improvement in air quality with respect to reduction of 49-73\%, 17-63\%, 30-74\%, and 15-58\% in the mean concentration of $\mathrm{PM} 2.5, \mathrm{PM} 10, \mathrm{NH}_{3}$, and $\mathrm{SO}_{2}$ respectively during the confinement for the studied locations. The $p$ values for all of the four studied locations were found significantly less than the 5\% level of significance for Welch's $t$ test analysis. In addition, reduced AQI values were highly correlated with prominent pollutants (PM2.5 and PM10) during Pearson's correlation analysis. These positive results due to pandemic imprisonment might aid to alter the current policies and strategies of pollution control for a safe and sustainable environment.
\end{abstract}

Keywords Air quality index $\cdot$ COVID-19 pandemic confinement $\cdot$ Pearson correlation analysis $\cdot$ Welch's $t$ test analysis

\section{Introduction}

COVID-19 crisis is caused by coronavirus 2 (SARS-CoV-2), a severe acute respiratory syndrome (Jandrić 2020). Currently, India is undergoing a 4.0 phase of confinement and has 190,649 confirmed COVID-19 cases and 5406 deaths until May 31, 2020 (covid19india.org). Confinement in India or

Responsible Editor: Marcus Schulz

Gaurav Pant

rgauravpant@gmail.com; gaurav.pant@gla.ac.in

1 Department of Biotechnology, Institute of Applied Sciences \& Humanities, G.L.A. University, Mathura, Uttar Pradesh, India

2 Department of Mathematics and Statistics, Banasthali Vidyapith, Banasthali, Rajasthan, India

3 National Centre for Coastal Research, Ministry of Earth Sciences (MoES), Govt. of India, Chennai, India

4 Department of Environmental Science, Asutosh College (Estd. 1916), Kolkata, West Bengal, India

5 Amity University, Noida, Uttar Pradesh, India any part of the world ensures that all transportation, factories, construction work, restaurants, and other social places should be closed to follow the social distancing on a serious note. These confinement phases not only help to control the spreading of infection, but also offer improvement in planetary health.

Air pollution is a major subgroup of environmental pollution which poses a serious threat to the ecosystem. The risk of global sustainability can be reduced by controlling anthropogenic activities responsible for the emission of air pollutants in the environment. India accounts for having one of the most polluted capitals and cities within the globe (Guttikunda et al. 2019). During a study conducted by the Central Pollution Control Board (CPCB), the Ministry of Environment, India confirmed significant impact of 1-day confinement in the country (March 22, 2020), named as "Janata Curfew" of $14 \mathrm{~h}$ from 7 a.m. to 9 p.m., on air quality in terms of reducing pollutant level when compared with previous day data (Barkur and Vibha 2020) (source CPCB, India).

Keeping in view the above, in the present study, impact of COVID-19 confinement on air qualities among the populous site of four major metropolitan cities in India (i.e., site 1- 
ITO, Delhi; site 2-Worli, Mumbai; site 3-Jadavpur, Kolkata; and site 4-Manali Village, Chennai) were determined by evaluating alteration in PM2.5, PM10, $\mathrm{NO}_{2}, \mathrm{NH}_{3}$, $\mathrm{SO}_{2}, \mathrm{CO}$, and ozone level from January 1, 2020 to May 31, 2020. Pearson product-moment correlation coefficient (PPMCC)-based model analysis was also proposed which determine the impact of COVID-19 pandemic confinement on air quality. Overall pandemic confinement has allowed the environment for detoxifying and renews itself in a lesser human interference phase. Environmental analysts designate it as a silver lining in terms of decreased carbon and waste emission but recognize it as a flawed perspective due to the expectation that the AQI levels to return as the coronavirus vanish and in some cases, they could come back strongly.

\section{Origin of data set}

Air quality index (AQI) reports daily air quality and its elevated level is associated with public health risks (Szyszkowicz 2019). Based on different national quality standards and doseresponse relationships of pollutants, countries have different air quality indices (Zhang et al. 2020; Sofia et al. 2020). The Indian national air quality index considers eight pollutants (PM10, PM2.5, $\mathrm{NO}_{2}, \mathrm{SO}_{2}, \mathrm{NH}_{3}, \mathrm{CO}, \mathrm{O}_{3}$, and $\mathrm{Pb}$ ) with a 24hourly averaging period. It is subdivided into six categories i.e., good (0-50), satisfactory (51-100), moderately polluted (101-200), poor (201-300), very poor (301-400), and severe (401-500) as shown in Fig. 1 (Perera 2018; Ghorani-Azam et al. 2016). The sub-indices for individual pollutants at a monitoring location are calculated using its 24-hourly average concentration value (8-hourly in case of $\mathrm{CO}$ and $\mathrm{O}_{3}$ ) and health breakpoint concentration range. The worst sub-index is the AQI for that location (https://app.cpcbccr.com/AQI India/). An increment in AQI causes acute and chronic mode health concern especially in the older age people and in children (Januszek et al. 2020; Pant et al. 2020). Due to the COVID-19 pandemic confinement, there is a significant reduction in the level of such toxic pollutants globally (Selvam et al. 2020; Singh and Chauhan 2020).

In the present study, concentrations of different pollutants i.e., PM2.5 (diameter $<2.5 \mu \mathrm{m}$ ), PM10 (diameter $<10 \mu \mathrm{m}$ ), $\mathrm{NO}_{2}, \mathrm{NH}_{3}, \mathrm{SO}_{2}, \mathrm{CO}$, ozone, and air quality index (AQI) were acquired from open access internet sources provided by the Central Pollution Control Board (CPCB), Ministry of Environment, Forests, and Climate Change (https://app. cpcbccr.com/AQI_India/). The data were recorded daily from January 1, 2020 to May 31, 2020, which is subdivided into two groups: (a) pre-lockdown period-January 1, 2020 to
March 23, 2020, and (b) lockdown period-March 24, 2020 to May 31, 2020 at 17:00 IST among four different air quality monitoring stations of the $\mathrm{CPCB}$ for four major metropolitan cities in India i.e., site 1-ITO, Delhi, site 2-Worli, Mumbai, site 3-Jadavpur, Kolkata, and site 4-Manali Village, Chennai as shown in Fig. 2. For air quality assessment, \% variations of air pollutants during the confinement period were compared with pre-lockdown values.

The air quality index is a piecewise linear function of the pollutant concentration. At the boundary between AQI categories, there is a discontinuous jump of one AQI unit. To convert from concentration to $\mathrm{AQI}$, this equation is used:

$I=\frac{I_{\text {high }}-I_{\text {low }}}{C_{\text {high }}-C_{\text {low }}}\left(C-C_{\text {low }}\right)+I_{\text {low }}$

If multiple pollutants are measured, the calculated AQI is the highest value calculated from the above equation applied for each pollutant.where

I The (air quality) index,

C The pollutant concentration,

$C_{\text {low }}$ The concentration breakpoint that is $\leq C$,

$C_{\text {high }}$ The concentration breakpoint that is $\geq C$,

$I_{\text {low }} \quad$ The index breakpoint corresponding to $C_{\text {low }}$,

$I_{\text {high }}$ The index breakpoint corresponding to $C_{\text {high }}$.

Moreover, we have used unpaired Welch's two-sample $t$ test analysis to measure the statistically significant reduction in average AQI for all four sites, as $t$ test allows us to compare the average values of the two data sets and determine if they came from the same population. The formula for calculating $\mathrm{t}$ statistics is given as:

$t=\frac{\bar{x}_{1}-\bar{x}_{2}}{\sqrt{\frac{s_{1}^{2}}{n_{1}}-\frac{s_{2}^{2}}{n_{2}}}}$

where, $\bar{x}_{1}$ and $\bar{x}_{2}$ are the sample means, $n_{1}$ and $n_{2}$ are the sample sizes, and $s_{1}^{2}$ and $s_{2}^{2}$ are the sample variances for samples 1 and 2 respectively.

To find out the most prominent pollutant concerning AQI statistically, we have done Pearson's correlation analysis by the means of plotting heatmaps corresponding to each site. Pearson's correlation is also known as the "product-moment correlation coefficient" (PMCC) and is suitable for measuring the extent of the linear relationship between any two quantitative variables statistically. A Pearson's correlation is a number ranging between -1 and +1 showing negative to positive linear correlation. Given a pair of random variables $\left(X_{1}, X_{2}\right)$,
Fig. 1 Indian national air quality index - category and range

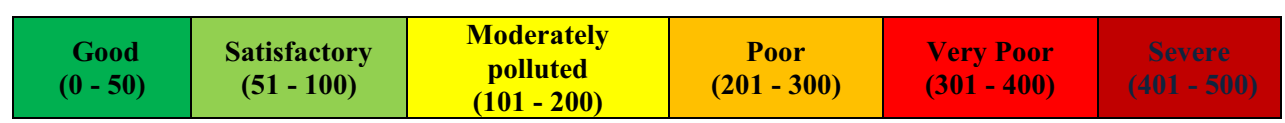




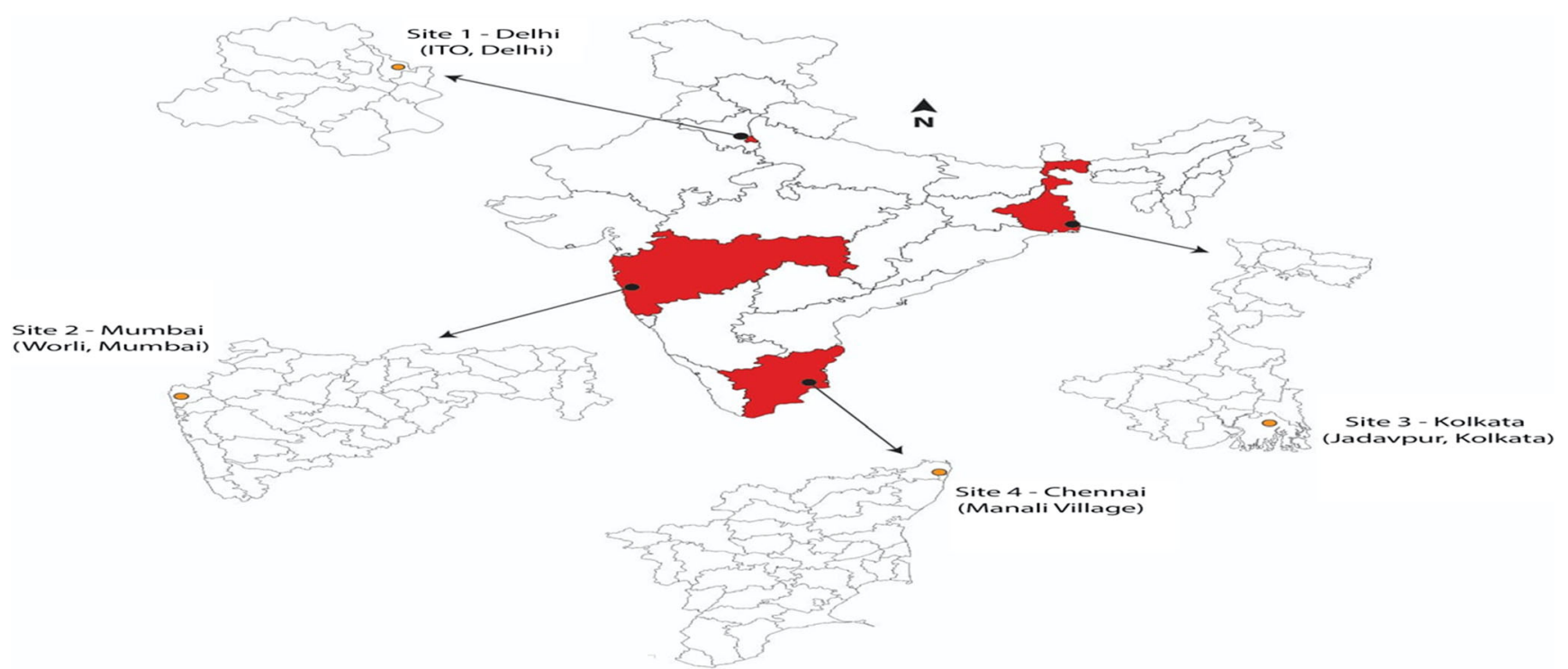

Fig. 2 The geography of monitoring stations among the populous sites of four major metropolitan cities in India

the formula for Pearson's correlation is given by

$\rho_{X_{1}, X_{2}}=\frac{\operatorname{Cov}\left(X_{1}, X_{2}\right)}{\sigma_{X_{1}} \sigma_{X_{2}}}$

where $\operatorname{Cov}\left(X_{1}, X_{2}\right)$ is the covariance between the variables under study and $\sigma_{X_{1}}, \sigma_{X_{2}}$ are the standard deviation of $X_{1}$, $X_{2}$ respectively.

\section{Analysis}

\section{Comparative study of AQI}

In the present investigation, the AQI level was at its highest peak on year starting among all of the four studied sites i.e., 443 in site 1, 298 in site 2, 292 in site 3, and 166 in site 4 . Initial data indicates Delhi was in the hazardous range while poor air quality in other states. Although irregular declining pattern was observed in the AQI level for all of the studied locations, a significant reduction within the pollutant level can be seen after comparing initial and final values. A remarkable drop falls of $44 \%, 59 \%, 59 \%$, and $6 \%$ in mean concentration of AQI which was observed during COVID-19 pandemic confinement for sites $1,2,3$, and 4 respectively as shown in Fig. 3.

\section{Comparative study of air pollutants}

\section{Site 1-ITO, Delhi}

Delhi, India's capital, is a massive metropolitan state in the northern area of the country and is among one of the most polluted capitals in the globe. Due to overpopulation and other responsible factors for urbanization, the pessimistic anthropogenic impact on the environment is at maximum. But, COVID-19 pandemic confinement facilitates the environment to retain its health which can be observed as a significant reduction in the air pollutant level in Delhi. At site 1-ITO, Delhi, during confinement period, the mean concentrations of PM2.5, PM10, $\mathrm{NO}_{2}, \mathrm{NH}_{3}$, and $\mathrm{SO}_{2}$ significantly plummeted by $49 \%, 33 \%, 29 \%, 63 \%$, and $24 \%$ respectively due to reduction in anthropogenic activities including traffic and manufacturing industries. Besides, due to high temperature and insolation during the confinement period, mean ozone concentration was highly elevated by $109 \%$ as shown in Table 1.

\section{Site 2-Worli, Mumbai}

Mumbai, the sixth most populous city in the world, is located on India's west coast and is the capital of Maharashtra. It is the financial, entertainment, and commercial center of India. During COVID-19 pandemic confinement, the second most populated city of India i.e., Mumbai has moved from poor to a satisfactory level of air quality. As initially at site 2 , the values of the pollutants which were scattered around $200-300 \mu \mathrm{g} / \mathrm{m}^{3}$ before confinement fallen to less than $60 \mu \mathrm{g} / \mathrm{m}^{3}$ during the confinement period (Fig. 4). The mean concentration of $\mathrm{PM} 2.5, \mathrm{PM} 10, \mathrm{NO}_{2}, \mathrm{NH}_{3}, \mathrm{SO}_{2}$, and $\mathrm{CO}$, significantly reduced with a percentage of $73,47,86,58,58,55$, and 60 respectively due to shutdown of navigation activities and other industrial sectors with automobile transportation (Table 1). The drastic decline in nitrogen oxide levels over Mumbai is the result of reduced carbon-emission hotspots, industrial and coal combustion-dominated areas. A decrease in the concentration of urban ground-level ozone was recorded by $60 \%$ due to high reduction in nitrogen oxide concentration in the atmosphere. 


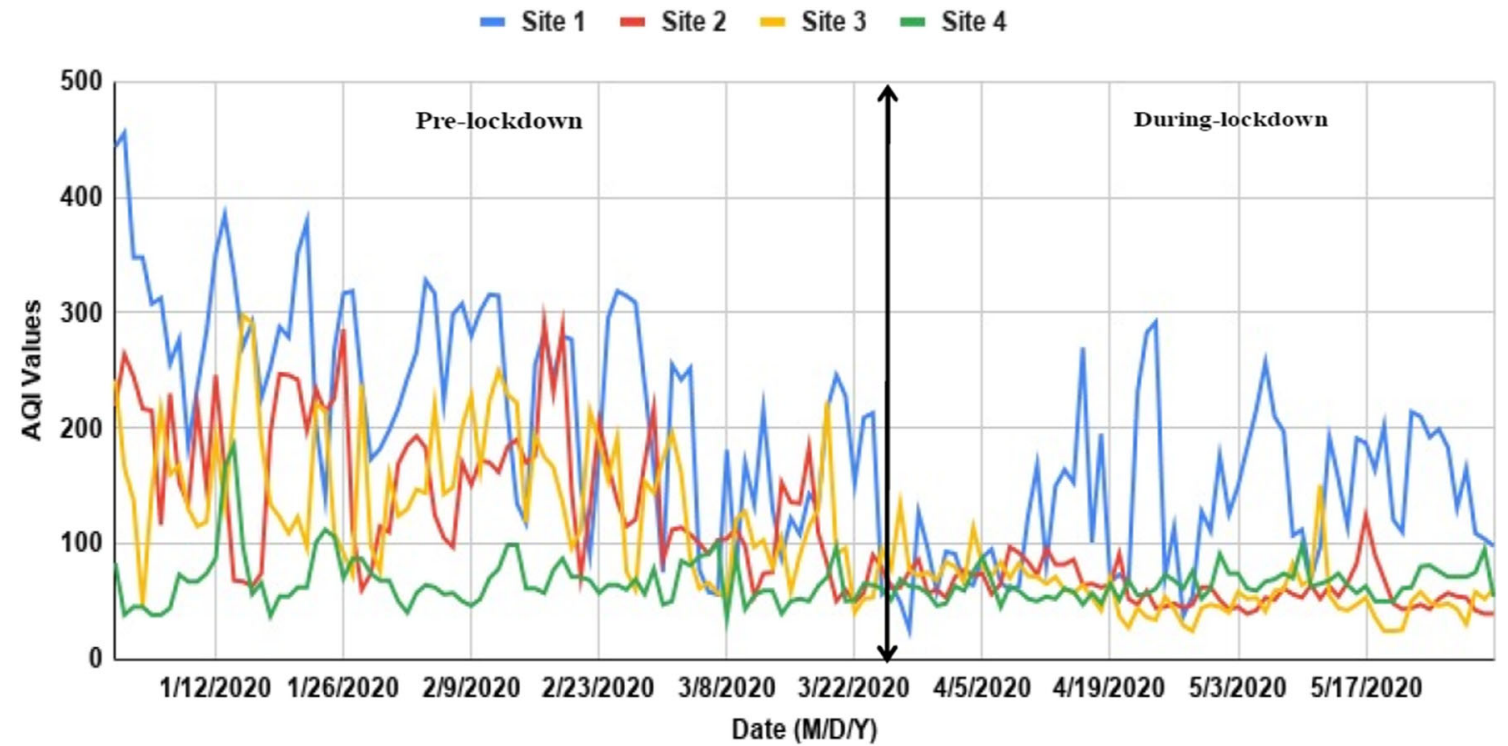

Fig. 3 Comparative AQI levels during pre-lockdown and lockdown period at 17:00 IST among four different air quality monitoring stations of the CPCB for four major metropolitan cities in India (site 1-ITO, Delhi,

\section{Site 3-Jadavpur, Kolkata}

After Delhi and Mumbai, Kolkata is the third populous metropolitan area in the nation. Kolkata is the educational, cultural, and commercial center of the eastern part of the country and is the capital of West Bengal. The concentration of $\mathrm{PM}$ 2.5, $\mathrm{PM} 10, \mathrm{NO}_{2}, \mathrm{NH}_{3}, \mathrm{SO}_{2}$, and $\mathrm{CO}$ at site 3 significantly dropped steeply from $242,205,85,10,9$, and $49 \mu \mathrm{g} / \mathrm{m}^{3}$ as on January 1,2020 to $20,28,9,1,7$, and $22 \mu \mathrm{g} / \mathrm{m}^{3}$ during COVID-19 pandemic confinement on May 31, 2020, respectively. Also, the mean concentration levels of PM2.5, PM10, $\mathrm{NO} 2, \mathrm{NH} 3, \mathrm{SO} 2$, and $\mathrm{CO}$ significantly reduced by $73 \%, 63 \%$, $79 \%, 74 \%, 15 \%$, and $32 \%$ due to decline in fossil fuel site 2-Worli, Mumbai, site 3-Jadavpur, Kolkata, and site 4-Manali Village, Chennai)

consumption, biomass burning, and other anthropogenic activities as observed from Fig. 4, while ozone levels were significantly raised by $77 \%$ with total variation of $+22 \mu \mathrm{g} / \mathrm{m}^{3}$ during confinement period as similar to Delhi due to high winds, intermittent rains and thunderstorms, and high temperature and heatwaves.

\section{Site 4-Manali Village, Chennai}

Chennai, the capital of Indian state of Tamil Nadu, is the fourth urban agglomeration in the nation and is the 36th largest urban area by population in the world. It is located on the Coromandel Coast off the Bay of Bengal and is center for the

Table 1 Air quality assessment — variations and change (\%) of average concentrations for different air pollutants during the pre and COVID-19 pandemic confinement, 2020 among populous sites of four major metropolitan cities in India

\begin{tabular}{|c|c|c|c|c|c|c|c|c|c|c|c|c|}
\hline \multirow[t]{2}{*}{ Pollutants } & \multicolumn{4}{|c|}{ Pre-lockdown values } & \multicolumn{4}{|c|}{ Lockdown } & \multicolumn{4}{|c|}{ Variation and $\%$ change (pre-lockdown and lockdown) } \\
\hline & Site 1 & Site 2 & Site 3 & Site 4 & Site 1 & Site 2 & Site 3 & Site 4 & Site 1 & Site 2 & Site 3 & Site 4 \\
\hline AQI & 238 & 151 & 144 & 68 & 134 & 62 & 59 & 64 & $-104(44 \%)$ & $-89(59 \%)$ & $-86(59 \%)$ & $-4(6 \%)$ \\
\hline PM2.5 & 238 & 132 & 135 & 56 & 122 & 36 & 36 & 26 & $-116(49 \%)$ & $-96(73 \%)$ & $-99(73 \%)$ & $-30(54 \%)$ \\
\hline PM10 & 150 & 116 & 122 & 60 & 100 & 61 & 45 & 49 & $-50(33 \%)$ & $-54(47 \%)$ & $-77(63 \%)$ & $-10(17 \%)$ \\
\hline $\mathrm{NO}_{2}$ & 44 & 48 & 55 & 9 & 31 & 7 & 11 & 10 & $-13(29 \%)$ & $-41(86 \%)$ & $-43(79 \%)$ & $1(7 \%)$ \\
\hline $\mathrm{NH}_{3}$ & 10 & 2 & 8 & 14 & 4 & 1 & 2 & 9 & $-6(63 \%)$ & $-1(58 \%)$ & $-6(74 \%)$ & $-4(30 \%)$ \\
\hline $\mathrm{SO}_{2}$ & 19 & 12 & 11 & 14 & 14 & 5 & 9 & 9 & $-4(24 \%)$ & $-7(58 \%)$ & $-2(15 \%)$ & $-6(39 \%)$ \\
\hline $\mathrm{CO}$ & 53 & 28 & 33 & 25 & 84 & 13 & 22 & 35 & $31(59 \%)$ & $-15(55 \%)$ & $-11(32 \%)$ & $9(37 \%)$ \\
\hline $\mathrm{O}_{3}$ & 35 & 85 & 29 & 36 & 73 & 34 & 51 & 65 & $38(109 \%)$ & $-51(60 \%)$ & $22(77 \%)$ & $29(80 \%)$ \\
\hline
\end{tabular}

PM2.5 in $\mu \mathrm{g} / \mathrm{m}^{3}$, PM10 in $\mu \mathrm{g} / \mathrm{m}^{3}, \mathrm{CO}$ in $\mu \mathrm{g} / \mathrm{m}^{3}, \mathrm{NH}_{3}$ in $\mu \mathrm{g} / \mathrm{m}^{3}, \mathrm{NO}_{2}$ in $\mu \mathrm{g} / \mathrm{m}^{3}, \mathrm{SO}_{2}$ in $\mu \mathrm{g} / \mathrm{m}^{3}$, and $\mathrm{O}_{3}$ in $\mu \mathrm{g} / \mathrm{m}^{3}$

$A O I$ air quality index 


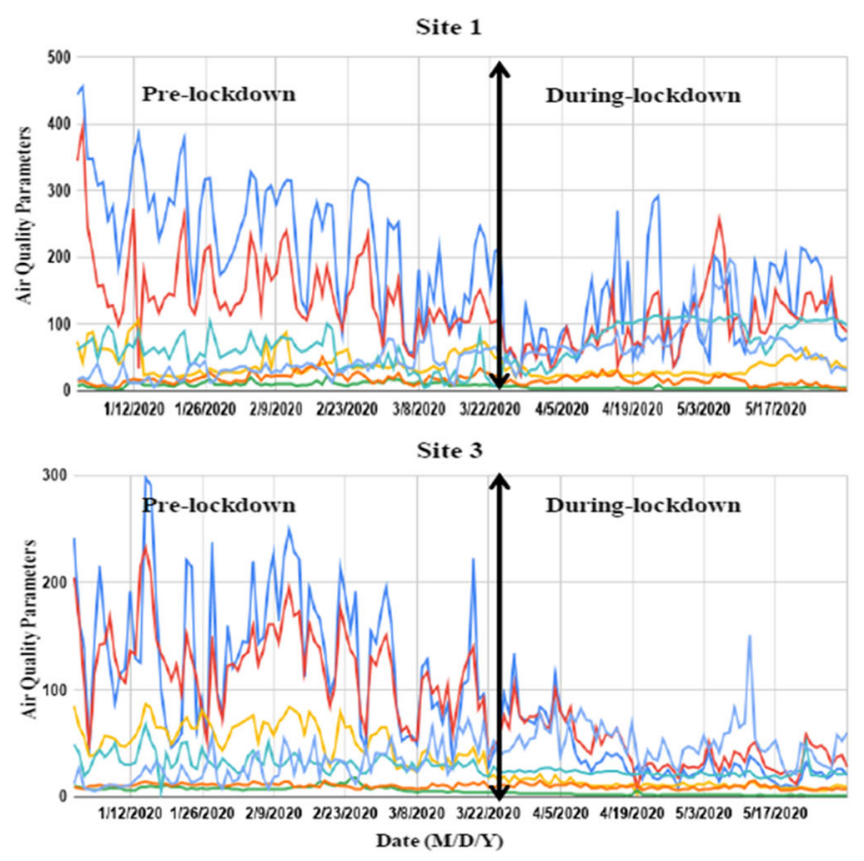

Fig. 4 The concentration of air pollutants (PM2.5 in $\mu \mathrm{g} / \mathrm{m}^{3}$, PM10 in $\mu \mathrm{g}$ / $\mathrm{m}^{3}, \mathrm{CO}$ in $\mu \mathrm{g} / \mathrm{m}^{3}, \mathrm{NH}_{3}$ in $\mu \mathrm{g} / \mathrm{m}^{3}, \mathrm{NO}_{2}$ in $\mu \mathrm{g} / \mathrm{m}^{3}, \mathrm{SO}_{2}$ in $\mu \mathrm{g} / \mathrm{m}^{3}$, and $\mathrm{O}_{3}$ in $\mu \mathrm{g} / \mathrm{m}^{3}$ ) during pre-lockdown and lockdown period at 17:00 IST among

cultural, economical, and educational activities of south India. Similar to all other studied sites, the air quality of site 4Manali Village, Chennai also confirmed improvement in terms of reduction in pollutant level during the confinement period. The mean concentrations of $\mathrm{PM} 2.5, \mathrm{PM} 10, \mathrm{NH}_{3}$, and $\mathrm{SO}_{2}$ were reduced by $54 \%, 17 \%, 30 \%$, and $39 \%$ respectively as shown in Fig. 4, while due to fuel and coal burning, vehicular emissions, and continuous functioning of power plants in the neighborhood of site 4 , there was no significant reduction in $\mathrm{NO}_{2}\left(+1 \mu \mathrm{g} / \mathrm{m}^{3}\right), \mathrm{CO}\left(+9 \mu \mathrm{g} / \mathrm{m}^{3}\right)$, and ozone levels (+ $29 \mu \mathrm{g} / \mathrm{m}^{3}$ ) (https://www.cag.org.in/blogs/air-quality-chennaiduring-lockdown-do-we-have-clues-mitigate-air-pollution).

\section{Pearson correlation analysis}

The Pearson correlation coefficient was determined by constructing a heatmap for the concentration of various pollutants (pre and during pandemic confinement) among populous sites of four metropolitan cities of India, viz. ITO, Delhi, Worli, Mumbai, Jadavpur, Kolkata, and Manali Village, Chennai.

\section{Site 1-ITO, Delhi}

At this site, the perfect positive correlation was observed between AQI and PM2.5, a strong positive correlation between AQI-PM10 and PM2.5-PM10, whereas a negative correlation was observed for ozone with AQI and other pollutants. The
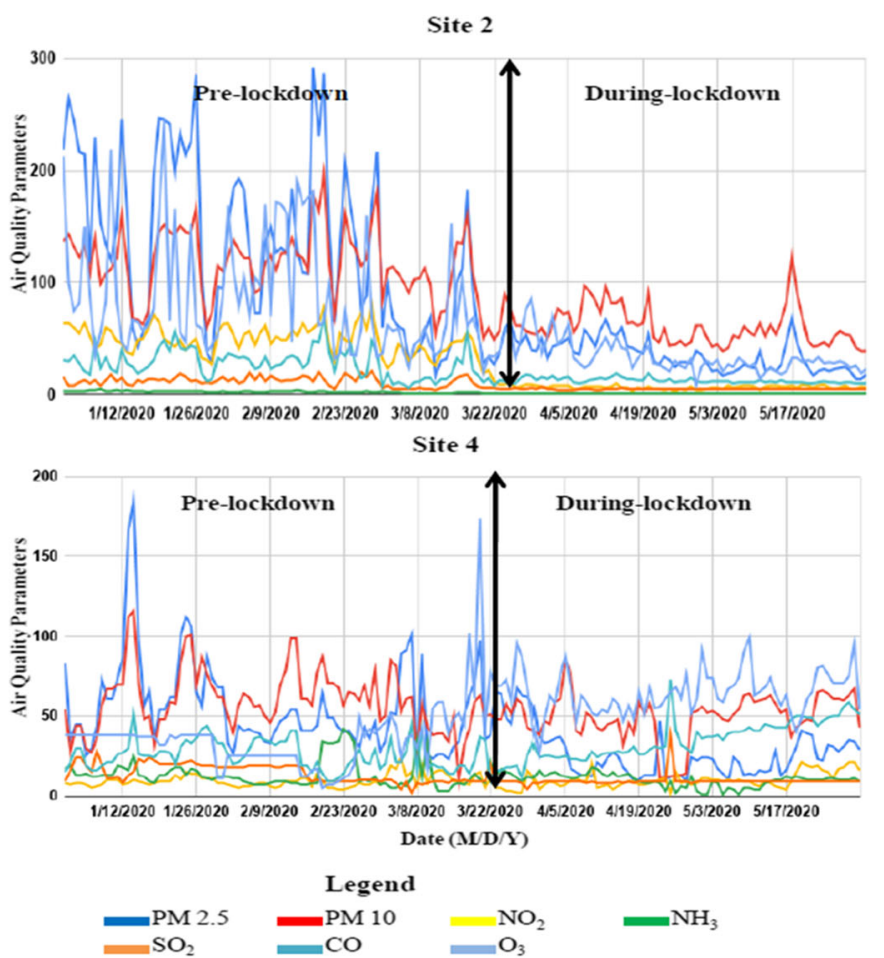

four different air quality monitoring stations of the CPCB for four major metropolitan cities in India (site 1-ITO, Delhi, site 2-Worli, Mumbai, site 3-Jadavpur, Kolkata, and site 4-Manali Village, Chennai)

correlation coefficient between AQI-PM2.5, AQI-PM10, and PM2.5-PM10 was found as $0.98,0.82$, and 0.77 respectively, showing a significantly higher positive relationship. This indicate the changes in PM2.5 and PM10 concentrations have a great influence on AQI content; i.e., an increase in their concentration will directly elevate the air quality index. Besides, AQI-ozone, PM2.5-ozone, and PM10-ozone confirmed low negatively correlated variables, i.e., $-0.31,-0.38$, and -0.18 respectively indicating the higher values of AQI, PM2.5, and PM10 will lower down the ozone concentration. A feeble correlation exists between AQI-NH $\mathrm{N}_{3}(0.46), \mathrm{AQI}-\mathrm{NO}_{2}$ (0.38), AQI-SO 2 (0.28), and AQI-CO (0.11) showing mild effect on AQI (Fig. 5 (a)).

\section{Site 2-Worli, Mumbai}

Product-moment correlation coefficient analysis for site 2 demonstrates the positive correlation between all of the studied pollutants as shown in Fig. 5 (b). The highest correlations were confirmed between AQI-PM2.5, with a correlation of 0.97, AQI-PM10, with 0.94, and PM2.5-PM10, with 0.91 which demonstrates PM2.5 and PM10 are the most significant dominating factors in elevating the AQI. A correlation value of $0.80,0.74,0.72$, and 0.86 between AQI-NO ${ }_{2}, \mathrm{AQI}-\mathrm{NH}_{3}$, $\mathrm{AQI}-\mathrm{SO}_{2}$, and AQI-CO indicates a significant positive relationship, while moderate correlation was determined between $\mathrm{CO}$ and ozone concentration (0.53). 
Fig. 5 Pearson's correlation heatmap for air pollutants during the pre and COVID-19 pandemic confinement, 2020 among populous sites of four major metropolitan cities in India
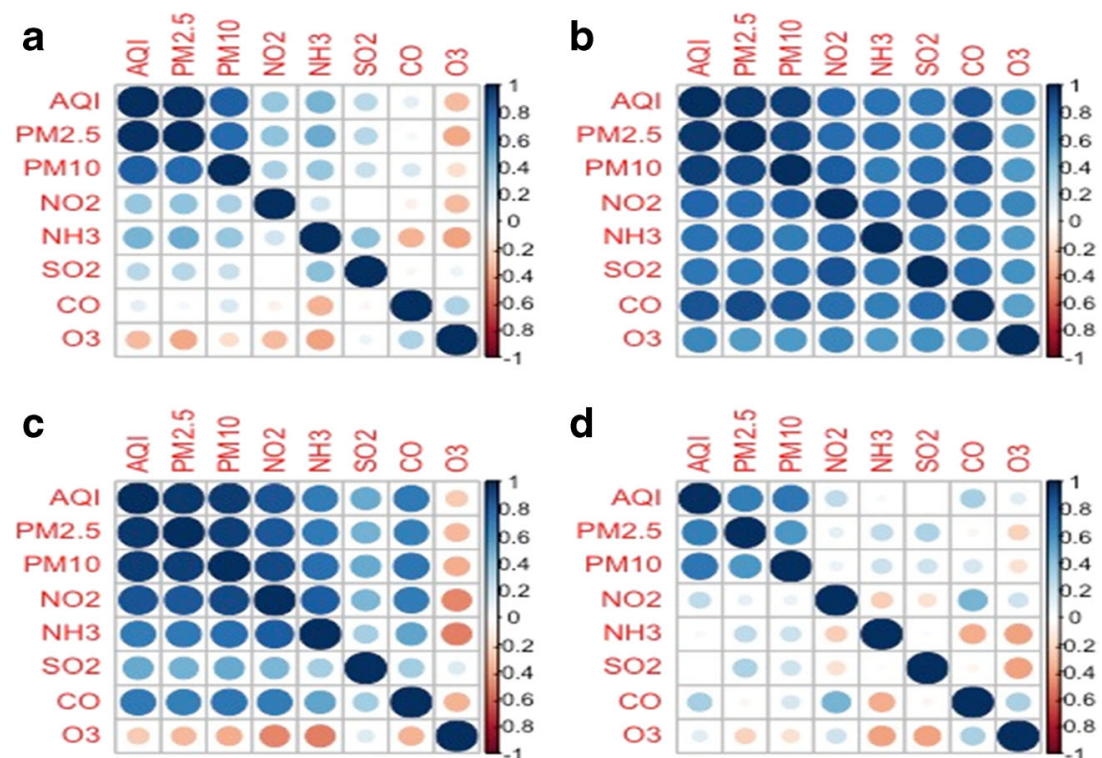

\section{Site 3-Jadavpur, Kolkata}

A significant positive correlation was observed between the prominent pollutants PM2.5, PM10, $\mathrm{NO}_{2}, \mathrm{NH}_{3}$, and $\mathrm{CO}$ with $\mathrm{AQI}$, i.e., $0.96,0.95,0.86,0.70$, and 0.70 respectively in site 3 as shown in Fig. 5 (c). This implies the studied pollutants had a great impact on air quality among monitoring station of Jadavpur, Kolkata, whereas ozone shows a negative correlation with AQI $(-0.25)$, and other studied pollutants i.e., PM2.5 (-0.32), PM10 (-0.36), $\mathrm{NO}_{2}(-0.48), \mathrm{NH}_{3}(-0.50)$, and $\mathrm{CO}(-0.35)$. This indicates mean $\mathrm{O}_{3}$ concentration will significantly increase with a decrease in the mean AQI, PM2.5, PM10, $\mathrm{NO}_{2}$, $\mathrm{NH}_{3}$, and $\mathrm{CO}$ concentrations.

\section{Site 4-Manali Village, Chennai}

Pearson's correlation heatmap for Manali Village, Chennai demonstrates significant positive correlations for PM2.5 (0.69) and PM10 (0.73) with AQI, while other pollutants exhibit a moderate or negative correlation. The lowest values of correlation coefficient were found for the pairs AQI-NO $\mathrm{N}_{2}(0.26), \mathrm{AQI}-\mathrm{NH}_{3}(0.04)$, and AQI-CO (0.33) indicating mild association between these variables; i.e., the effect of concentration of $\mathrm{NO}_{2}, \mathrm{NH}_{3}$, and $\mathrm{CO}$ on air quality is minimal. However, the approximately zero correlation between AQI-SO $\mathrm{S}_{2}(0.009)$ and AQIozone (0.01) indicates no linear relationship, but there may be some other strong non-linear relationship between the two variables (Fig. 5 (d)). In other words, we can say that the simple linear function cannot describe its relationship in depth.

\section{Inferential t-statistic (Welch's two-sample $t$ test)}

In the present study, the significant impact of COVID-19 pandemic confinement on air quality in studied locations was determined by right-tailed, Welch's two-sample $t$ test. The complete data set was divided into two groups, preconfinement (A) and during confinement (B) to assess if there is a statistically significant effect of confinement on AQI. Independent random samples of sizes $n_{1}, n_{2}$ were drawn by using a random number table from both the groups and applied $t$ test using the R-software. This inferential statistic was used to test the following hypothesis:

$H_{0}$ : No significant difference between the means of two groups i.e., no significant effect of COVID-19 pandemic confinement on AQI $\left(\mu_{1}=\mu_{2}\right)$.

$H_{\mathrm{A}}$ : Significant difference between the means of two groups i.e., air quality is significantly improved during COVID-19 pandemic confinement $\left(\mu_{1}>\mu_{2}\right)$, where $\mu_{1}$ and $\mu_{2}$ are the population means of the two groups.

From Table 2, we can observe that the t-statistic (5.91), which when compared with critical $t$ value (1.67) at 5\% level of significance $(\alpha)$, rejected the null hypothesis and confirmed the significant reduction in the AQI for site 1 . The $p$ value was also found to be very small, suggesting that the COVID-19 pandemic confinement reduced AQI (45\%). The $p$ value revealed it is "unlikely" that we would observe such an extreme test statistic $t^{*}$ in the direction of $H_{\mathrm{A}}$ if the null hypothesis was true. Therefore, the initial assumption that the null hypothesis is true must be incorrect. That is, since the $p$ value, 0.00000015 , is very less than $\alpha=0.05$, we reject the null 
Table 2 Welch's two-sample $t$ test analysis

\begin{tabular}{|c|c|c|c|c|c|c|c|c|}
\hline & \multicolumn{2}{|l|}{ Site 1} & \multicolumn{2}{|l|}{ Site 2} & \multicolumn{2}{|l|}{ Site 3} & \multicolumn{2}{|l|}{ Site 4} \\
\hline & Sample A & Sample B & Sample A & Sample B & Sample A & Sample B & Sample A & Sample B \\
\hline Mean & 241.65 & 134.25 & 159.12 & 65.77 & 144.86 & 57.45 & 75.78 & 63.20 \\
\hline Observations & 36 & 35 & 36 & 35 & 36 & 35 & 36 & 35 \\
\hline Hypothesized mean difference & \multicolumn{2}{|l|}{0} & \multicolumn{2}{|l|}{0} & \multicolumn{2}{|l|}{0} & \multicolumn{2}{|l|}{0} \\
\hline Degree of freedom & \multicolumn{2}{|l|}{62} & \multicolumn{2}{|l|}{38} & \multicolumn{2}{|l|}{40} & \multicolumn{2}{|l|}{42} \\
\hline $95 \%$ confidence interval & \multicolumn{2}{|c|}{$(71.05,143.75)$} & \multicolumn{2}{|c|}{$(69.45,116.99)$} & \multicolumn{2}{|c|}{$(63.14,111.65)$} & \multicolumn{2}{|l|}{$(1.09,24.05)$} \\
\hline t-statistic & \multicolumn{2}{|l|}{5.91} & \multicolumn{2}{|l|}{7.94} & \multicolumn{2}{|l|}{7.28} & \multicolumn{2}{|l|}{2.20} \\
\hline $\mathrm{P}(T \leq t)$ one-tail & \multicolumn{2}{|c|}{0.00000015} & \multicolumn{2}{|c|}{0.0000000014} & \multicolumn{2}{|c|}{0.0000000074} & \multicolumn{2}{|l|}{0.03} \\
\hline$t$ Critical one-tail & \multicolumn{2}{|l|}{1.67} & \multicolumn{2}{|l|}{1.68} & \multicolumn{2}{|l|}{1.68} & \multicolumn{2}{|l|}{1.68} \\
\hline
\end{tabular}

hypothesis $H_{0}: \mu_{1}=\mu_{2}$ in favor of the alternative hypothesis $H_{\mathrm{A}}: \mu_{1}>\mu_{2}$. However, if we lowered our willingness to make a type I error to $\alpha=0.01$ instead, the significant rejection of the null hypothesis is again observed. This is due to reduction in anthropogenic activities including fuel and coal burning, vehicular emissions, and manufacturing industries.

The same behavior can be observed from the data of Table 2 for 2 nd, 3 rd, and 4th studied locations where the much lowered $p$ values exhibited the statistically significant effect of COVID-19 pandemic confinement in lowering the sample mean AQI by $58 \%, 60 \%$, and $17 \%$ respectively.

\section{Conclusion}

The present study demonstrates the impact of COVID-19 pandemic confinement on air quality among the populous site of four major metropolitan cities in India i.e., site 1-ITO, Delhi, site 2-Worli, Mumbai, site 3-Jadavpur, Kolkata, and site 4-Manali Village, Chennai. A data set was constructed for AQI, PM2.5, PM10, $\mathrm{NO}_{2}, \mathrm{NH}_{3}, \mathrm{SO}_{2}, \mathrm{CO}$, and ozone from January 1, 2020 to May 31, 2020 from the Central Pollution Control Board (CPCB). Pearson's correlation analysis and Welch's $t$ test were performed for the determination of statistically significant improvement in the air quality during the confinement period. A remarkable drop falls of 44\%, 59\%, $59 \%$, and $6 \%$ in AQI which was observed during COVID19 pandemic confinement in sites $1,2,3$, and 4 respectively. It can be concluded that remarkable improvement in the air quality during confinement period was observed as the $p$ values of the test for all of the four sites were very less than the significance level ( $\alpha=0.05)$. Besides, the Welch's $t$ test was supported by findings of Pearson's correlation analysis in which the prominent pollutants (PM2.5 and PM10) were also found to be highly correlated with AQI. Although a significant impact on planetary health can be noticed during COVID-19 pandemic confinement, the circumstance is momentary and limits for a short duration i.e., only up to confinement period.
Acknowledgments The authors are grateful to the Central Pollution Control Board (CPCB), Ministry of Environment, Forests, and Climate Change, India for providing open access to internet sources which help in the construction of data set for the current study. The authors would like to convey their sincere thanks to the management of G.L.A. University, Mathura (U.P.), India, Department of Mathematics and Statistics, Banasthali Vidyapith, Banasthali, Rajasthan, India, National Centre for Coastal Research, Ministry of Earth Science (MoES), Govt. of India, Chennai, India, Department of Environmental Science, Asutosh College (Estd. - 1916), Kolkata, West Bengal, India, and Amity University, Noida, Uttar Pradesh, India for providing facilities.

Authors' contribution All authors have a specific role in the current research and have contributed to the preparation of the article. Preparation of the data set was performed by Dr. Gaurav Pant, Dr. Alka, and Dr. Deviram Garlapati. The validation and effectiveness of the proposed models were studied by Dr. Gaurav Pant, Dr. Alka, Dr. Kaizar Hossain, and Mr. Ashish Gaur, while Dr. Gaurav Pant, Dr. Alka, Dr. SV Singh, and Dr. AK Gupta were actively involved in article structure and analysis.

Data availability The data sets analyzed during the current study are available in the open access internet sources provided by the Central Pollution Control Board (CPCB), Ministry of Environment, Forests, and Climate Change (https://app.cpcbccr.com/AQI_India/).

\section{Compliance with ethical standards}

Conflict of interest The authors declare that they have no conflict of interest.

Consent to participate Not applicable.

Consent to publish Not applicable.

\section{References}

Barkur G, Vibha GBK (2020) Sentiment analysis of nationwide lockdown due to COVID 19 outbreak: evidence from India. Asian J Psychiatr 12:102089. https://doi.org/10.1016/j.ajp.2020.102089

Ghorani-Azam A, Riahi-Zanjani B, Balali-Mood M (2016) Effects of air pollution on human health and practical measures for prevention in Iran. J Res Med Sci: the official journal of Isfahan University of Medical Sciences 21:65. https://doi.org/10.4103/1735-1995.189646 
Guttikunda SK, Nishadh KA, Jawahar P (2019) Air pollution knowledge assessments (APnA) for 20 Indian cities. Urban Clim 27:124-141. https://doi.org/10.1016/j.uclim.2018.11.005

Jandrić P (2020) Postdigital research in the time of Covid-19. Postdigit Sci Educ 2:233-238. https://doi.org/10.1007/s42438-020-00113-8

Januszek R, Staszczak B, Siudak Z, Bartuś J, Plens K, Bartuś S, Dudek D (2020) The relationship between increased air pollution expressed as PM10 concentration and the frequency of percutaneous coronary interventions in patients with acute coronary syndromes - a seasonal differences. Environ Sci Pollut Res 27:21320-21330. https://doi. org/10.1007/s11356-020-08339-6

Pant G, Yadav DP, Gaur A (2020) ResNeXt convolution neural network topology-based deep learning model for identification and classification of Pediastrum. Algal Res 48:101932. https://doi.org/10.1016/ j.algal.2020.101932

Perera F (2018) Pollution from fossil-fuel combustion is the leading environmental threat to global pediatric health and equity: solutions exist. Int J Environ Res Public Health 15(1):16. https://doi.org/10. 3390/ijerph15010016

Selvam S, Muthukumar P, Venkatramanan S, Roy PD, Bharath KM, Jesuraja K (2020) SARS-CoV-2 pandemic lockdown: effects on air quality in the industrialized Gujarat state of India. Sci Total Environ 737:140391. https://doi.org/10.1016/j.scitotenv.2020. 140391

Singh RP, Chauhan A (2020) Impact of lockdown on air quality in India during COVID-19 pandemic. Air Qual Atmos Health 13:921-928. https://doi.org/10.1007/s11869-020-00863-1

Sofia D, Gioiella F, Lotrecchiano N, Giuliano A (2020) Mitigation strategies for reducing air pollution. Environ Sci Pollut Res 27:1922619235. https://doi.org/10.1007/s11356-020-08647-x

Szyszkowicz M (2019) The Air Quality Health Index and all emergency department visits. Environ Sci Pollut Res 26:24357-24361. https:// doi.org/10.1007/s11356-019-05741-7

Zhang N, Zhao K, Yu Y (2020) The effect of environmental regulation on air pollution, productivity, and factor structure: a quasi-natural experiment evidence from China. Environ Sci Pollut Res 27:2039220409. https://doi.org/10.1007/s11356-020-08462-4

Publisher's note Springer Nature remains neutral with regard to jurisdictional claims in published maps and institutional affiliations. 